\title{
Texture and motion spreading, the aperture problem, and transparency
}

\author{
TAKEO WATANABE and PATRICK CAVANAGH \\ Harvard University, Cambridge, Massachusetts
}

\begin{abstract}
When a cross of either static or moving texture is inserted in the intersection of an Ehrenstein figure, we find that the texture and its motion appear to spread outside of the cross. We suggest that these phenomena are analogous to neon color spreading, wherein an interpretation of a transparent surface makes the properties of that surface, which are physically visible only inside the cross, appear to spread over its apparent extent. In our experiments, the texture and the motion of the cross are attributed to the transparent surface. In addition, the spreading changes the apparent aperture within which the texture and its motion are seen, leading to a corresponding change in the apparent direction of motion.
\end{abstract}

The lines in the pattern shown in Figure 1a (Ehrenstein, 1941/1987) induce disk-shaped illusory surfaces within the area of missing intersections. When colored or gray crosses, which by themselves induce no interesting visual effect (Figure 1b), are inserted into the intersections of the Ehrenstein figure, the color of the crosses appears to spread out, filling up the illusory disks (Figure 1c). This visual illusion is known as the neon color-spreading effect (Redies, 1989; Redies \& Spillmann, 1981; van Tuijl, 1975).

Here we report that the texture and motion of the crosses inserted in the intersections may also spread outside the area of the crosses. In addition, we examine the effect that the change in the shape of the area of moving texture (the aperture) has on the apparent direction of the motion.

\section{EXPERIMENT 1}

\section{Texture Spreading}

\section{Method}

Subjects. Twelve subjects, 7 females and 5 males, of normal or corrected-to-normal visual acuity and of normal color vision participated in Experiment 1.

Stimulus. The stimuli were presented on a color video display $\left(23.0^{\circ} \times 17.25^{\circ}\right.$, Apple M0401, $640 \times 480$ pixel resolution) controlled by a Macintosh IIcx and viewed at a distance of $57.3 \mathrm{~cm}$. Four figures were used: (1) eight crosses with a texture made up of black and white diagonal stripes were inserted in the gaps of the Ehrenstein figure (Figure 2a); (2) the 8 textured crosses were presented in isolation (Figure 2b); and (3) and (4) were identical to (1) and (2) except that the diagonal texture was replaced with a texture of black and white dots (Figures $2 c$ and $2 d$ ). The stroke width of the black lines of the Ehrenstein figure and of the textured

This work was supported by JSPS Grant 1421 to Takeo Watanabe and AFOSR Grant 31-760-7409-2-30 to Patrick Cavanagh. We thank Barton Anderson, Walter Ehrenstein, Raynald Comtois, Jiro Hamada, Zijiang He, Ken Nakayama, Christoph Redies, Josée Rivest, Shinsuke Shimojo, and Hiroshige Takeichi for their suggestions regarding our research and manuscript. Correspondence should be addressed to Takeo Watanabe, Department of Psychology, Harvard University, William James Hall, 33 Kirkland Street, Cambridge, MA 02138. crosses was $10^{\prime}$ in visual angle. Both the height and the width of the crosses were $1^{\circ} 12^{\prime}$. The center-to-center distance between the intersections was $2^{\circ} 44^{\prime}$ vertically and horizontally. The widths of the black and white stripes of the striped texture were $4^{\prime}$ of arc. The stripes were oriented at $45^{\circ}$. The size of the white dot elements of the $38 \%$ density dotted texture against the black background was $4^{\prime}$ square. The luminance of the black lines and the black parts of the texture was $1.0 \mathrm{~cd} / \mathrm{m}^{2}$, and that of the background and the white parts of the texture was $100.0 \mathrm{~cd} / \mathrm{m}^{2}$.

Procedure. The subjects were asked to fixate at the central intersection of the vertical and horizontal black lines in Figures $2 a$ and $2 c$ and at the small fixation cross at the center in Figures $2 b$ and $2 \mathrm{~d}$. They had to indicate whether the texture of the crosses appeared to spread outside of the crosses or not. If they answered "yes," they were further asked if the expanded texture area was defined by a clear contour. If they again answered "yes," they were asked to describe the shape of the contour. The four figures were presented in a different random order to each subject. The experimental session was conducted in a dark room.

\section{Results}

Table 1 shows, for the striped or dotted texture with the Ehrenstein figures (Figures $2 a$ and $2 c$ ) and the striped or dotted texture without the Ehrenstein figures (Figures $2 \mathrm{~b}$ and $2 \mathrm{~d}$ ), the percentage of the subjects who saw the texture spread outside the crosses as well as the percentage of those who saw a well-defined contour surrounding an expanded area of texture. All subjects who saw the contour reported that it was circular. For the striped and dotted texture crosses, the percentages of the subjects who saw the texture spreading were significantly higher when the textured crosses were embedded in the Ehrenstein figures than when they were presented alone $(z=$ $4.14, p<.01$, for the striped texture, and $z=3.79$, $p<.01$, for the dotted texture; $z=$ critical ratio).

The percentages of subjects who saw well-defined contours were also significantly higher for the textured crosses embedded in the Ehrenstein figures than for the textured crosses alone $(z=4.14, p<.01$, for the striped texture, and $z=2.19, p<.05$, for the dotted texture). These results suggest that the Ehrenstein figures are necessary for the texture-spreading effect. 


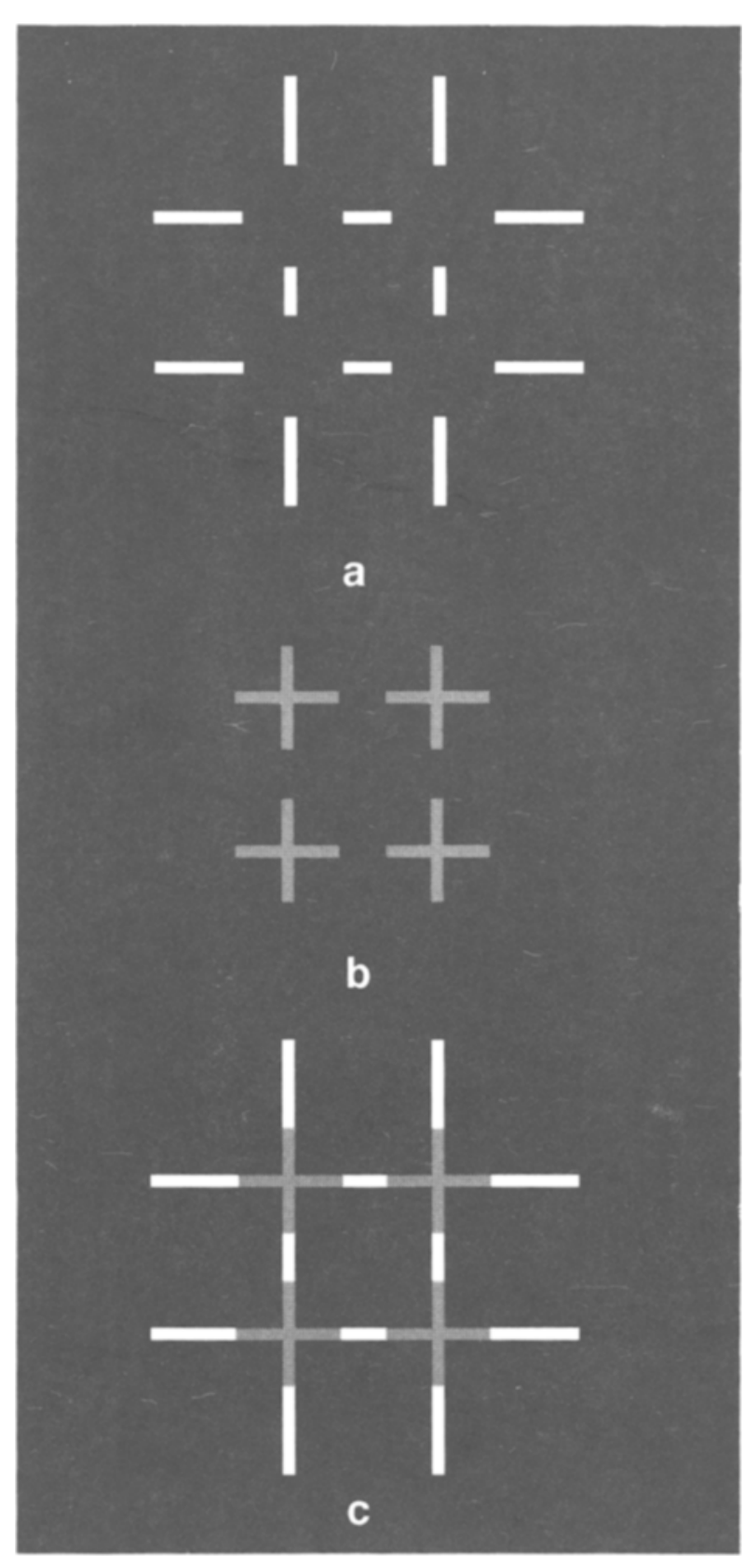

Figure 1. (a) The Ehrenstein figure-radially arranged lines induce lllusory disks between their inner tips. (b) Gray crosses that, on their own, appear as gray crosses. (c) If the gray crosses from panel b are inserted into the gaps of the Ehrenstein figure, the brightness (and color, if different) of the crosses is seen to spread out to fill an illusory disk in a visual illusion known as the neon colorspreading effect.

We made several additional informal observations to explore the differences and similarities between texture spreading and the neon color spreading that occurs when the intersections are colored rather than textured (Redies \& Spillmann, 1981).

First, weakened neon color spreading persists when the colored crosses and the Ehrenstein figure are set to equi- luminance. The illusory contours, however, are not seen (Watanabe \& Sato, 1989). Similarly, when the average luminance of texture and the luminance of the Ehrenstein figure were equalized in our stimulus, all observers (5) reported texture spreading but none saw illusory contours. The texture spreading was less extensive than it was in the main experiment, in which the crosses and the Ehrenstein figure had different luminance values. This observation suggests that either the presence of illusory contours or conditions that induce them accentuate both texture and color spreading (see Watanabe \& Takeichi, 1990).

Second, Redies and Spillmann (1981) reported that the disconnection between the inserted colored cross and limbs of the Ehrenstein figure considerably reduced the neon color-spreading effect. Figure 3 shows that the same tendency occurs with texture spreading.

Finally, when the colored cross was foveated in the neon color stimulus, color spreading persisted (Redies \& Spillmann, 1981). On the other hand, texture spreading totally disappeared when a textured cross was foveated. The possible reason for this difference between color spreading and texture spreading will be discussed in more detail in the final section.

\section{EXPERIMENT 2 Motion Spreading}

In Experiment 1, we found that texture appeared to spread outside the crosses when they were placed in the Ehrenstein figure. In Experiment 2, the texture inside the crosses was made to move while the form of the crosses remained stationary, so that we could examine whether the motion would also appear to spread outside the crosses.

\section{Method}

Subjects. The 12 subjects from Experiment 1 took part in Experiment 2.

Stimulus. Two figures were used: (1) Four crosses made up of drifting diagonal luminance gratings were inserted in the gaps of the Ehrenstein figure (Figure 4a); (2) the same 4 crosses were shown in isolation (Figure $4 \mathrm{~b}$ ). The gratings consisted of the repetition of white $\left(100.0 \mathrm{~cd} / \mathrm{m}^{2}\right)$, gray $\left(43.2 \mathrm{~cd} / \mathrm{m}^{2}\right)$, black $\left(1.0 \mathrm{~cd} / \mathrm{m}^{2}\right)$, and gray stripes. The width of each stripe was $4^{\prime}$ of arc. The velocity of the gratings was $.4 \% \mathrm{sec}$. The stroke width of the black lines of the Ehrenstein figure and of the crosses was $12^{\prime}$ in visual angle. Both the height and width of the crosses were $2^{\circ}$. The center-tocenter distance between the intersections was $2^{\circ} 36^{\prime}$ vertically and horizontally. Other details of the stimuli were identical to those of the previous experiment.

Procedure. When each figure was presented, the subjects were asked whether the texture of the luminance gratings in the crosses appeared to spread outside of the crosses. If they answered "yes," they were further asked whether they saw any motion outside the crosses. Half of the subjects saw the crosses in the Ehrenstein figure first and then the crosses alone, and the other half of the subjects saw the reverse order. The other aspects of the experimental procedure were identical to those of Experiment 1.

\section{Results}

When the crosses were inserted in the Ehrenstein figure, all 12 subjects saw the texture not only spreading but also moving outside the crosses. When, on the other hand, the 


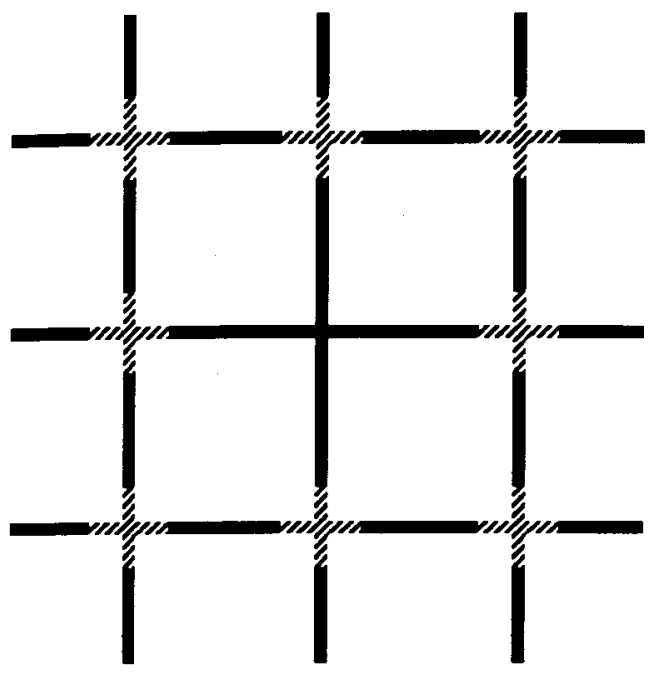

a

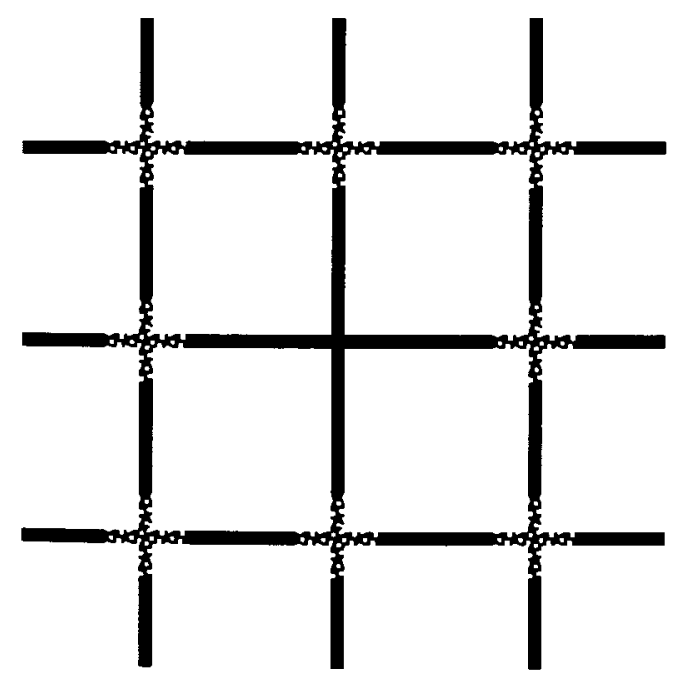

C

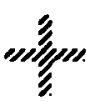

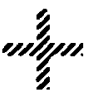<smiles>CC(C)(C)C</smiles>

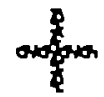

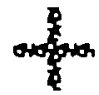<smiles>CC(C)(C)[Mg]</smiles>

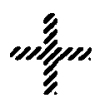<smiles>[Li][13CH3]</smiles><smiles>CC(C)(C)C</smiles>

b<smiles>CC(C)(C)C</smiles>

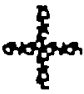<smiles>[CH]1CC1</smiles>

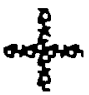

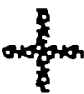<smiles>CC(C)(C)C</smiles>

Figure 2. (a) Crosses filled with a texture of black and white diagonal stripes inserted into the gaps of the Ehrenstein figure. (b) The crosses of striped texture presented alone. (c) Crosses filled with a black and white dotted texture inserted in the gaps of the Ehrenstein figure. (d) The croeses of dotted texture presented alone. To observe the spreading effect, fixate the central cross in each case.

crosses were presented alone, no subject saw the texture either spreading or moving outside of the crosses $(z=$ $4.90, p<.01$, for both texture and motion).

\section{EXPERMMENT 3 \\ Change in Motion Direction with Motion Spreading}

The spread of the motion outside the crosses in Experiment 2 brings with it a change in the shape of the aperture within which the motion is seen. The effect of aper-
Table 1

Percentage of Subjects Who Perceived Spreading and Contours

\begin{tabular}{llcc}
\hline & & \multicolumn{2}{c}{ Percent of Subjects } \\
\cline { 3 - 4 } $\begin{array}{c}\text { Type of } \\
\text { Texture }\end{array}$ & Effect & $\begin{array}{c}\text { With } \\
\text { Ehrenstein }\end{array}$ & $\begin{array}{c}\text { Without } \\
\text { Ehrenstein }\end{array}$ \\
\hline Stripes & Spreading & 83.3 & $0 \dagger$ \\
Sriptes & Contours & 83.3 & $0+$ \\
Dots & Spreading & 75.0 & $0 \dagger$ \\
Dots & Contours & 33.3 & $0^{*}$ \\
\hline
\end{tabular}

Note $-n=12$ for each condition. Significant difference between with and without: ${ }^{*} p<.05,+p<.01$. 

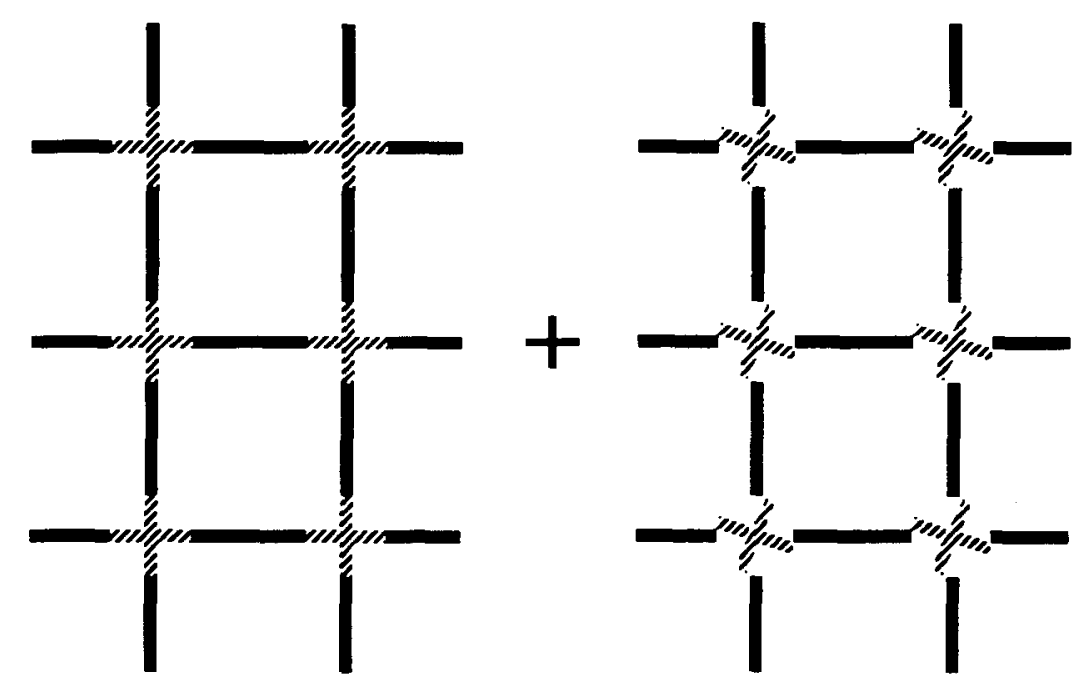

Figure 3. Six textured crosses collinearly connected with the Ehrenstein figures to the left of the fixation point, and six textured crosses whose outlines are rotated by $22.5^{\circ}$ in the Ehrenstein figures to the right. Compare the texture spreading seen in the left and right figures during fixation of the central point.

ture shape on motion direction is well known as the barber pole effect (Wallach, 1935). Diagonal stripes are seen to move orthogonally to their orientation when viewed through a circular aperture, but when seen in a rectangular aperture, they appear to move in the direction of the longer side. The aperture shape of the crosses is complex, but subjects did report that motion seemed to flow along the arms of the crosses, horizontally and vertically, when the crosses were seen alone. In Experiment 3, we examined the effect of presentation-alone or embedded in the gaps of the Ehrenstein figure-on the perceived direction of motion of the texture in the crosses.

\section{Method}

Subjects. The subjects from the previous experiments served in Experiment 3.

Stimulus. The stimuli were identical to those used in Experiment 2.

Procedure. The subjects were asked to report the dominant perceived direction or directions of the diagonal texture seen in Figures $4 \mathrm{a}$ and $4 \mathrm{~b}$. The other aspects of the experimental procedure were identical to those of Experiment 2.

\section{Results}

When the crosses were inserted in the Ehrenstein figure, 11 of 12 subjects reported that diagonal motion was dominant. The remaining subject reported that the dominant motion was vertical and horizontal in the vertically and horizontally elongated parts of the crosses, respectively. When the crosses were presented alone, on the other hand, 10 of 12 subjects reported that the dominant motion was vertical and horizontal in vertically and horizontally elongated parts of the crosses, respectively. The remaining 2 did not report any motion in the crosses. The percentage of the subjects who saw diagonal motion dominantly in the textured crosses embedded in the Ehrenstein figure

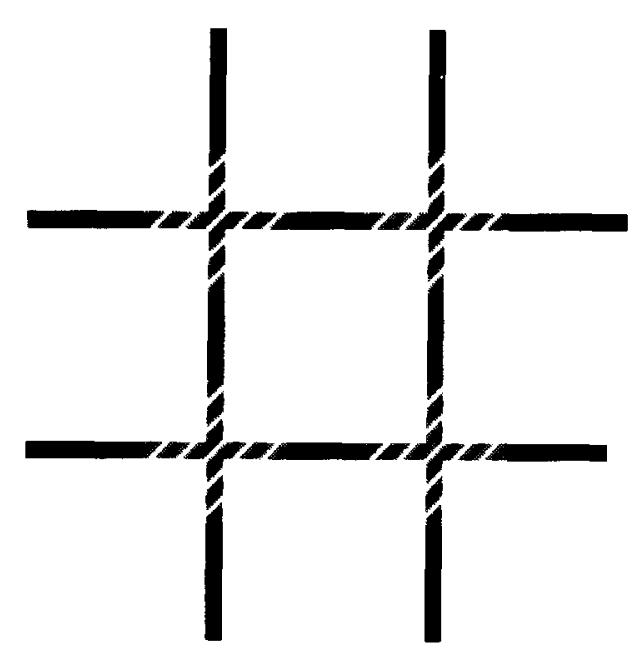

a
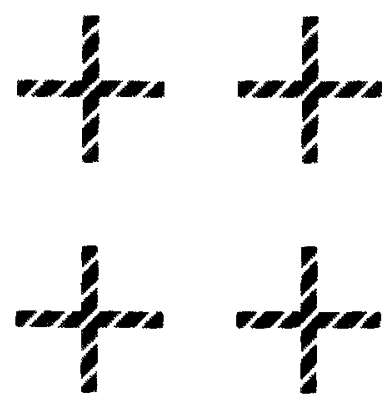

b

Figure 4. (a) Crosses filled with a texture of diagonal luminance gratings inserted into the gaps of the Ehrenstein figure. (b) The crosses of the luminance gratings presented alone. In both displays, the texture drifted, but the cross-shnped apertures within which the texture was presented did not move. 
was significantly higher than the percentage who saw diagonal motion in the textured crosses alone $(z=4.51$, $p<.01)$.

With motion present in the cross-shaped apertures alone, the perceived motion direction was influenced by the elongated contours of the arms of the crosses. On the other hand, when the moving texture appeared to spread outside the cross-shaped apertures, the physical shape of the apertures no longer controlled the perceived motion direction.

\section{GENERAL DISCUSSION}

In Experiments 1 and 2, we showed that texture and motion spread outside the crosses inserted in the gaps of the Ehrenstein figure, whereas there was no spreading when the crosses were presented alone. These results extend the phenomenon of spreading to qualities of texture and motion in addition to that reported for color and brightness in the neon color-spreading effect (Redies \& Spillmann, 1981).

Several authors have suggested that there is a close relationship between the neon color-spreading effect and transparency (de Weert \& van Kruysbergen, 1987; Grossberg, 1987; Meyer \& Senecal, 1983; Nakayama \& Shimojo, 1990; Ramachandran, 1990; Redies \& Spillmann, 1981; Takeichi, Shimojo, \& Watanabe, in press). For example, in Figure 1c, the color in the crosses appears to be separated into color in transparent disks and white lines of the underlying grid. This feature separation is characteristic of perception of transparency (Beck, Prazdny, \& Ivry, 1984; Metelli, 1974; Watanabe \& Cavanagh, 1991, in press).

Why do these figures generate transparency? Some authors (Nakayama \& Shimojo, 1990; Ramachandran, 1990) have argued that it is an example of choosing the most likely interpretation. In Figure 1c, for example, the exact alignment of a cross of one color with the lines of a different color is a rather unlikely event. A more likely interpretation is that a transparent disk overlies a continuous regular grid, covering the intersection. For the particular stimulus values of Figure 1c, the effect of the transparent disk is visible only where it overlies the lines of the grid and not at all where it overlies the background. ${ }^{1}$ We suggest that the spreading of texture and motion that we have observed in our figures may also be mediated by a subjective transparency-but one that involves static or drifting textures. They appear to lie over the black lines of the grids. In this case, the texture is only visible when silhouetted against the lines of the grid but is attributed as well to the areas outside the grid lines.

Attributing colors and textures to locations where they are physically absent should most likely occur at locations where the visual system is relatively insensitive to their presence. For example, color and brightness can fill in when there is a large uniform area of one color and brightness, since uniform color and brightness signals are strongly attenuated by antagonistic center-surround mechanisms. If other cues suggest an overlying surface of a particular color or brightness, the available neural signal cannot easily contradict the inferred values. On the other hand, local texture elements are quite visible throughout a textured region as long as the elements are above resolution threshold. Center-surround mechanisms do not suppress textures. Texture should be most clearly visible in the fovea and less so in the periphery, implying that the texture filling generated by transparency interpretations should occur most readily in the periphery. Thus, texture filling should and does occur in scotomas (Teuber, 1978), the blind spot (Kawabata, 1984), and the periphery (Kawabata, 1990; Ramachandran \& Gregory, 1991), where no contradictory neural signal can be generated. On the other hand, texture filling should be unlikely in the fovea, as we observed for foveated intersections of Figures $2 \mathrm{a}$ and $2 \mathrm{c}$ or a textured version of the Varin figures. In the original Varin (1971) figure, the otherwise incomplete disks of a Kanizsa triangle were completed with colored sectors, and a faint impression of this color filled the subjective triangle. When we substituted textured sectors for the colored ones, no texture spreading was observed. This figure is typically inspected at its center, however, so that the region in which texture might be inferred falls directly on the fovea, thereby suppressing the texture filling. In other figures where the subjective surfaces were in the periphery and where the gaps between textured regions were less extensive, we regularly observed texture filling.

Zucker and his colleagues (Hel Or \& Zucker, 1990; Link \& Zucker, 1987; Zucker, 1985) have described a different kind of texture spreading where the texture fills in between texture elements. What we report here is texture spreading or filling in between texture regions.

In our final experiment, the change in the direction of perceived motion could be understood by considering the shape of the apparent apertures. When no spreading was seen for the crosses alone, the physical apertures imposed horizontal and vertical directions on the motion of the stripes. When the texture appeared to spread outside the physical crosses, the apparent apertures became more circular and reduced its biasing effect on the perceived direction of motion. Note that if the effect of the texture spreading on the apparent apertures occurred after the decision about motion direction, the perception of vertical and horizontal motion should not have been abolished by the change in apparent apertures. It has been suggested that at least some aspects of the barber pole effect are mediated by area MT in the macaque (Bülthof, Little, \& Poggio, 1989; Shimojo, Silverman, \& Nakayama, 1989). Thus, texture spreading may involve processes at or prior to MT.

In conclusion, we found that static and moving textures spread outside of the cross inserted in the intersection of an Ehrenstein figure. We suggest that the interpretation of a transparent surface makes the properties of that surface, which are physically visible only inside the cross, appear to spread over its apparent extent most notably in the peripheral retina, where the sensitivity to the presence 
or absence of the texture is lower. The spreading changed the shape of the apparent aperture within which the texture and its motion were seen, leading to a corresponding change in the apparent direction of motion.

\section{REFERENCES}

Beck, J., Prazdny, K., IVry, R. (1984). The perception of transparency with achromatic colors. Perception \& Psychophysics, 35 , 407-422.

Bülthoff, H., Litrle, J., \& Poggio, T. (1989). A parallel algorithm for real-time computation of optical flow. Nature, 337, 549-553.

De Weert, C. M. M., \& van Kruysbergen, N. A. W. H. (1987). Subjective contour strength and perceptual superimposition: Transparency as a special case. In S. Petry \& G. E. Meyer (Eds.), The perception of illusory contours (pp. 165-170). New York: SpringerVerlag.

Ehrenstein, W. (1987). Modifications of the brightness phenomenon of L. Hermann (Anne Hogg, Trans.). In S. Petry \& G. E. Meyer (Eds.), The perception of illusory contours (pp. 35-39). New York: Springer-Verlag. (Original work published in 1941 as Uber Abwandlungen der L. Hermannschen Helligkeitserscheinung. Zeitschrift fur Psychologie, 150, 83-91)

GrossberG, S. (1987). Cortical dynamics of three-dimensional form, color, and brightness perception: II. Binocular theory, Perception \& Psychophysics, 41, 117-158.

HeL OR, Y., ZUCKER, W. S. (1990). Texture fields and texture flows: Sensitivity to differences. Spatial Vision, 4, 131-139.

KAWABATA, N. (1984). Perception at the blind spot and similarity grouping. Perception \& Psychophysics, 36, 151-158.

KAWABATA, N. (1990). Structural information processing in peripheral vision. Perception, 19, 631-636.

LINK, N., ZUCKER, S. W. (1987). Sensitivity to corners in flow patterns. Spatial Vision, 2, 233-244.

Metelli, F. (1974). The perception of transparency. Scientific American, 230, $90-98$.

Meyer, G. E., Senecal, M. (1983). The illusion of transparency and chromatic subjective contours. Perception \& Psychophysics, 34, 58-64.

Nakayama, K., \& Shimojo, S. (1990). Towards a neural understanding of visual surface representation. In Cold Spring Harbor Symposia on Quantitative Biology: Vol. LV (pp. 911-924). Cold Spring Harbor Laboratory Press.

Ramachandran, V. S. (1990). Visual perception in people and machines. In A. Blake \& T. Troscianko (Ed.), AI and eye (pp. 2177). New York: Wiley.

Ramachandran, V. S., Gregory, R. L. (1991). Perceptual filling in of artificially induced scotomas in human vision. Nature, 350, 699-702.

RediEs, C. (1989). Discontinuities along lines: Psychophysics and neurophysiology. Neuroscience \& Behavioral Reviews, 13, 17-22.

Redies, C., \& SpillmanN, L. (1981). The neon color effect in the Ehrenstein illusion. Perception, 10, 667-681.
Shimojo, S., Silverman, G. H., Nakayama, K. (1989). Occlusion and the solution to the aperture problem for motion. Vision Research, 29, 619-626.

Takeichi, H., Shimojo, S., W Watanabe, T. (in press). Localization of the process for color filling-in in the neon color spreading. Perception.

Teuber, H.-L. (1978). The brain and human behavior. In R. Held, H. W. Leibowitz, \& H.-L. Teuber (Eds.), Handbook of sensory physiology: Vol.8. Perception (pp. 879-920). Berlin: Springer-Verlag.

VAN TUIJL, H. F. J. M. (1975). A new visual illusion: Neonlike color spreading and complementary color induction between subjective contours. Acta Psychologica, 39, 441-445.

VARUN, D. (1971). Fenomeni di contrasto e diffusione chromatica nell' organizzazione spaziale del campo percettivo. Rivista di Psicologia, 65, 101-128.

WALLACH, H. (1935). Über visuell wahrgenommene Bewegungsrichtung. Psychologische Forschung, 20, 325-380.

Watanabe, T., SATo, T. (1989). Effects of luminance contrast on color spreading and illusory contour in the neon color spreading effect. Perception \& Psychophysics, 45, 427-430.

Watanabe, T., TAKEICHI, H. (1990). The relation between color spreading and illusory contours. Perception \& Psychophysics, 47, 457-467.

Watanabe, T., Cavanagh, P. (1991). Transparency facilitates recognition of overlapping stimuli even for very short exposures. Investigative Ophthalmology \& Visual Science, 32, 2508.

Watanabe, T., Cavanagh, P. (in press). Effect of duration of subjective transparency using the pattern identification task. Perception.

ZUCKER, S. W. (1985). Early orientation selection: Tangent fields and the dimensionality of their support. Computer Vision, Graphics, \& Image Processing, 32, 74-103.

\section{NOTE}

1. Neon color spreading is also observed with colored crosses embedded in black Ehrenstein figures on a white background (Redies \& Spillmann, 1981). Although this cannot correspond to a filter-type transparency, it does have a physical model in the translucent surface that reflects one part of the spectrum and transmits the remainder, such as a dichroic mirror. The visual system might therefore interpret the Redies and Spillmann figure as translucent disks that overlie the intersections of a black grid on a white background. The colored light reflected from the translucent disks is additively mixed with light reflected back from the grid, so that where the disks overlie the black lines of the grid, only the saturated color reflected from the disks is seen. Where the disks overlie the white background, the light reflected from the disks is remixed with the remainder of the spectrum that was transmitted through the disks, reflected from the underlying white background and back through the translucency a second time, producing white.

(Manuscript received February 28, 1991; revision accepted for publication July 15, 1991.) 